\title{
MAINTENANCE SCHEDULING: DESCRIPTION, STATUS AND FUTURE DIRECTIONS
}

\author{
S. A. Oke \\ Department of Mechanical Engineering, University of Lagos, Nigeria \\ sa_oke@yahoo.com
}

\begin{abstract}
In the past several decades, there have been diverse and significant research activities on maintenance scheduling (MS) due to the multi-disciplinary dimension of the field. As a consequence of this diversity and multi-disciplinary involvement, the MS literature is at present fragmented, somewhat misleading, and deficient in informative articles that cover the length, breadth, and depth of scientific investigations in the field. This paper reviews the scientific discipline of MS, covering general surveys, models, and significant empirical studies and cases in MS research. The research reflects the multidisciplinary nature of work in the field and suggests areas for future investigation.
\end{abstract}

\section{OPSOMMING}

In die afgelope aantal dekades was daar uiteenlopende en aansienlike navorsingsbedrywigheid op die gebied van instandhoudingskedulering (IS) weens die multidissiplinêre dimensie van die gebied. As gevolg van hierdie diversiteit en multidissiplinêre betrokkenheid is die ISliteratuur tans gefragmenteer, ietwat misleidend en gebrekkig aan insiggewende artikels wat die lengte, breedte en diepte van wetenskaplike ondersoeke op die gebied dek. Hierdie artikel bied 'n oorsig oor die wetenskaplike vakgebied van IS en dek algemene opnames, modelle en aansienlike empiriese ondersoeke en gevalle in IS-navorsing. Die navorsing weerspieël die multidissiplinêre uitkyk van werk op dié gebied en open gebiede vir toekomstige navorsing. 


\section{INTRODUCTION}

Research on MS spans across disciplines and contains a wide range of theoretical developments, exploratory and conceptual models, theoretical grounded discussions, debates on methodology, and historical essays. It contains novel, insightful and carefully crafted articles that challenge conventional wisdom concerning all aspects of the field. Researchers and practitioners in the field of mathematics, computing, and engineering (i.e. electrical, highway, and industrial) dominate this field [46, 48, 67].

The MS literature spans a variety of applications. These diverse applications include aircraft maintenance [3, 74], process industry [4], vehicle fleet maintenance [23, 35, 36, 55], railway track maintenance [37, 39, 51, 52, 53], power generation [11, 16, 19, 42, 84], pavement maintenance [12, 32, 83], highway maintenance [82, 85], refinery [89, 90], and production facilities [40, 45, 61, 66]. An attempt to codify the MS literature portrays a line of inquiry that has grown in volume and in depth. Despite the immense resources allocated to the study of MS in the past 30 years, a more intensive study of some deep structures is still required.

This paper reviews the most popular MS literature in a way that reflects the characteristics of studies, and attempts to reveal the shortcomings of the existing frameworks. Specifically, the aims of this paper are: (i) to review the relevant research that has been undertaken to date, and (ii) to propose some priority research questions for members of the MS research community. No claims are made for the paper's comprehensiveness. Instead, the author hopes that the paper will stimulate debates within the MS and wider academic communities. This work provides the reader with insight into developments in the field of MS in general. It would be useful for future investigators involved in MS research who seek a broad-based understanding of the field. It is intended that the reader should be left with an understanding of the wide range of topics involved, an impression of the length and breadth of this interdisciplinary academic field, and the wide-ranging practical applications.

The present-day need for MS is now more important than ever before, and continues to grow constantly. Advances are continually being made in this field, due largely to the consistent competition in the international market requiring fast and efficient maintenance systems. Despite this, the MS field remains complicated - one that demands high-quality technical knowledge. To demonstrate the complexity of the scheduling problem, consider the general $\mathrm{N} / \mu / \mathrm{G} / \mathrm{B}$ job shop problem consisting of $m$ permutation of the $n$ jobs where the parameters $N$, $\mu, G$ and $B$ define the number of jobs, the number of machines, the general job-shop case and the performance measure by which the schedule should be evaluated. Here, each permutation gives the processing sequence of jobs on a particular machine. Now there is $n$ ! different permutations of $n$ objects. Since each of the permutations may be as different from the rest, it follows that the total number of schedules is (n!) ${ }^{\mathrm{m}}$. In a problem of 4 jobs and 4 machines, i.e. $\mathrm{n}=4$ and $\mathrm{m}=4$, the total number of schedules is (4!) $)^{4}$ i.e. 331776 . Here, we have a very small problem: only 4 machine and 4 jobs, yet the number of possible contenders for the solution is enormous. We might be able to check through the 331776 possibilities in a reasonable time on a fast computer if 1000 schedules were checked each second (which would be very fast), the computer would solve the problem in just over 5 minutes. But, suppose the number of machines was increased to 5 , the number of schedules would now be (5!) $)^{4}$ and the computer would take over 57 hours to solve this new problem! 
The paper is structured into different sections, each dealing with various aspects of the subject. First, a brief historical overview describing the evolution of MS is given. It also considers the literature and the problem areas and areas where MS is important.

\section{HISTORICAL REVIEW}

The honour of discovering great mathematical principles and theories that underlie the science of MS belongs to a number of noted investigators. Gerver [33] may be credited first. In early times, most maintenance researchers must have believed that scientific scheduling of facilities for maintenance in complex systems could be best achieved by intuition. It was Gerver, in 1972, who first conspicuously denied this doctrine of intuition and proposed the first elaborate theory of MS. A great advance followed as scientific principles were incorporated into scheduling by maintenance practitioners and researchers.

Unfortunately, the MS literature featured many mathematical derivations that limited its understanding only to researchers who were willing to master the intricacies of the mathematical formulations. Maintenance practitioners had no choice but to leave mathematical explorations and associated results to the mathematically inclined researchers. Sadly, maintenance practitioners were the best people who understood the problem and could best devise appropriate MS solutions. Assigning the task to researchers often resulted in less than ideal solutions. As a result, there was an urgent need to develop approaches that would permit greater access to MS by both practitioners and research workers. Consequently, the original approaches to solving MS problems would be considered crude by today's standards.

Also in the 1970s, Christiaanse [15] demonstrated to the scientific world the universal existence of MS problems with an unsurpassed array of evidence. He propounded a theory that is widely applied in scheduling maintenance. Suddenly, MS is everywhere. Academic journals experienced a proliferation of research papers on MS. New terms and theories (e.g. objective criteria, optimal values, MS constraints) emerged [31, 34]. An unintended consequence of the proliferation of research on MS during the 1970s was a lack of coherence in the field. Research on MS was in the initial period of experimentation, and a dominant paradigm was yet to be developed. Creativity and new ideas were rampant, but there was little integration among researchers. Also, little dialogue existed across disciplines.

In the 1980s, the dynamic scheduling theory formed the basis of empirical research. The foundation is found in the paper of two English researchers - Enscore and Burns [30], which has thrown much light on solving complex MS problems.

During the 1980s, interest in MS began to wax stronger, evidenced by an increase of more than $400 \%$ in the volume of publications in the field. In addition, prominent journals that now dominate the maintenance scene started to devote more attention to MS. Specialised journals that now address maintenance problems emerged during this decade with considerable focus on MS. The European Journal of Operational Research, Royal Naval Research Logistics, A.I.I.E. Transactions, SAIM Journal of Computing, Maintenance Management International, Quality and Reliability International, among others, prominently featured in MS studies. It was in this decade that the non-polynomial (NP)-hard concept was widely publicised and identified in MS problems. Consequently, it seems remarkable to credit Charles-Owaba [13] in a recent work for his novel attempt in developing an optimal solution for the NP-hard 
problem that had been unsolved for over 20 years.

Back in the 1980s, the impact of computers on MS with respect to data manipulation was very great. Multiple manipulations of data with computers for simple and complex problems were made possible and performable, thus eliminating difficulty and tediousness of the operations. Consequently, analysis and manipulations of data on MS have become more closely tied to computers with the introduction of microcomputers.

In the 1990s, Duffuaa and Ben-Daya [26] led in the discussion of MS for overhaul scheduling problems. Hariga [38] proposed solutions for scheduling non-identical machines. This is an important contribution to knowledge that has worked its way into the mainstream of both academia and business.

The 1990s experienced tremendous growth and changes in MS theory. For example, in the early stage of development of MS theory, it was normally announced that all maintenance jobs were available together at the beginning of the scheduling period and the activity times of all the maintenance jobs were known a priori. It was also traditional to solve problems so as to optimise single criteria. The 1990s experienced a turnaround on these assumptions. Researchers sought for cases in which not all maintenance activities start at the beginning of the scheduling period. Cases that optimise dual and multiple criteria were sought. Towards the close of the decade, studies were diverse and the growth could be described as unprecedented.

Furthermore, researchers tend to use different lenses to understand the practice of MS, depending on theoretical orientations. Like different schema, each of these lenses leads us to certain variables and relationships while ignoring others. Focusing multiple lenses on a given phenomenon highlights different aspects of that phenomenon. Each lens suggests a different set of practices and solutions to practitioners.

The year 2000 marked the beginning of another century that holds much promise for development in MS theory. It is expected that new and emerging business concepts will influence research interest in MS theory, creating more understanding. Research is predicted to reach its climax during the next millennium with interesting research findings.

In conclusion, an overview of the historical perspective of the MS literature over the past 30 years highlights many changes to the field. Early problems encountered by founding researchers have been overcome with the application of many new concepts. As a result, MS has matured to become an attractive field of research.

The light that early great researchers and pioneer MS scholars kindled must now be made to illuminate with added brilliance despite the complex industrial environment of today. Many fields of MS are practically virgin for scheduling investigators.

\section{MS LITERATURE}

This section provides a search and review of the MS literature conducted over the Internet, in research libraries, departmental outlets, relevant journals, and professional bodies worldwide. A detailed review was made to involve more than 30 journals, several scores of books, a 
substantial number of conference papers, workshop proceedings and unpublished postgraduate dissertations and theses (master's and $\mathrm{PhDs}$ ). The preliminary literature review informed our understanding that MS is a multidisciplinary field that cuts across fields such as mathematics, computing, civil engineering, transportation engineering, and industrial engineering. Hence, efforts were aimed primarily at these fields in order to discover the extent of work done on MS. The review has been conducted to include the entire major operations research journals in Europe, USA, Australia, India, Japan and other parts of the world. Specialist journals of a technical nature and journals dealing with some practical applications are noted. The review covers scholarly articles on MS from its beginning in the early 1970s through the present.

The influential paper of Encore and Burns [30] was one of the first widely accepted published works on MS in 1982. The paper demonstrated certain important principles in maintenance systems of large organisations with a substantial amount of inventory. Apart from the maintenance systems of manufacturing organisations, the research pointed to maintenance in service organisations as an important consideration. Encore and colleague therefore presented an actual study of the implemented system to demonstrate how all preventive inspections are scheduled, based on when exactly they were last done and not when they were supposed to have been done. The MS field was therefore presented as an important one that could be scientifically investigated. There was a call to abandon toy research on real problems and refocus on real research on real MS problems.

In a doctoral thesis, Yang [87] investigated single-machine job scheduling with scheduled preventive maintenance in which the problems can be categorised into two classes - fixed MS and flexible maintenance schedule. The make-span total flow-time and weighted total flowtime were investigated with single or double maintenance requirement. Yang treated a flexible maintenance schedule as having the maintenance starting time flexible within a time window. The flexible maintenance schedule problems deal with cases similar to fixed maintenance schedule problems, except that a general cost function is considered for each of the problems. Yang developed a dynamic programming (DP) algorithm for each problem to obtain the optimal solution. He developed two heuristics algorithms for each of the double maintenance requirement problems. From a total of 12 DP algorithms and 12 heuristic algorithms in his research, only one DP algorithm is based on the 0-1 knapsack problem. The experimental results showed that the heuristic algorithms perform very well - the maximum difference from the optimal solution is about $1 \%$.

Subsequently, a number of theoreticians proposed models for scheduling maintenance, which relates to a group of identical machines [9] and non-identical machines [25, 39]. Hariga [38] proposed that the problem could be approached heuristically with the use of a mixed integral non-linear program. In the model formulation, it is assumed that a major overhaul brings the machine back to its new condition, where a minor overhaul restores it to a specified operating condition. The author developed an iterative solution procedure to obtain a near-optimal cyclic overhaul schedule.

Duffuaa and Ben-Daya [26] proposed a model, which is similar to that of Hariga in that it focused on non-identical production units. The model is developed for the joint overhaul problem by incorporating the cost of coordination. The model selects overhaul schedules that minimise the average cost of production, and the cost of coordination. The model obtains 
lower costs of two examples. Among the deficiencies of these models is the fact that no evidence of the machine dominance concept is considered. Yet, in many instances, a dominating machine may be given preferential scheduling treatment in view of its influence on the production/service system considered. In addition, the treatment approach to a nonrenewable resource constraint situation may be different from those specified by these authors.

The work by Kobbacy and associates [43] is concerned with the development of a realistic preventive maintenance (PM) scheduling model. A heuristic approach to implementing the semi-parametric proportional-hazards model (PHM) to schedule the next preventive maintenance interval on the basis of the equipment's full condition history was introduced. These models are then used in a simulation framework to schedule the next preventive maintenance interval. The results indicate higher availability for the recommended schedule than the availability resulting from applying the optimal PM intervals as suggested by using the conventional stationary models.

Olorunniwo and Izuchukwu [69] applied the concept of maintenance improvement factors to preventive and overhaul maintenance. The authors developed mathematical models that are used to generate preventive and overhaul maintenance schedules. Examples are provided to demonstrate the sensitivity of the schedules to model parameters.

Ashayeri [4] reported on simultaneous planning of preventive maintenance and production in a process industry environment. The author developed a mixed integer linear programming model. The model schedules production jobs and preventive jobs, while minimising costs associated with production, backorders, corrective maintenance and preventive maintenance. The model takes into account the probability of a breakdown given by the last maintenance period. The formulation of the model is flexible, so that it can be adapted for several production situations. However, the deterministic model discussed does not afford insight into the nature of deterioration of machines. A common form of machine deterioration is stochastic but many studies have assumed linear deterioration for ease of modelling. The author also ignored the multicriterion nature of MS problems. In addition, he did not account for the robustness and sensitivity of the model formulated.

Since MS problems arise from situations that require assignments of resources over time to perform a set of activities, typically, these problems may be viewed as the determination of optimal sequence for the activities on the resources and vice-versa.

Silver and Murphy [77] analysed the sensitivity of an analytical formula, based on inspection scheduling to determine the duration of the preventive maintenance period. The cost penalties of this model are calculated compared to the exact solution that utilises the lifetime distribution in the derivation of the optimal preventive maintenance period. A simple extension of the heuristics is suggested to improve the approximation with a slightly increased computational effort. The sensitivity and the cost analysis of the improved heuristics are discussed as well.

In a very recent publication, Charles-Owaba [13] challenged the MS literature as lacking adequate solution procedures for solving NP-hard problems. He criticised the literature as only able to obtain near optimal solutions with the use of heuristics as against optimal 
solutions that guarantee effective decision-making. Drawing from the traditional wisdom of Gantt Charting, he evolved an optimal model for solving multiple facilities, multiple period MS problems. Specifically, he solved an M-machine, T-periods capacity constrained maintenance-operations scheduling problem by formulating it as an LP transportation model. The problem is to minimize the total preventive maintenance cost, $C\left(T, M, y_{i}\right)$, over all the machines, given limited periodic maintenance capacity $\left(A_{j}\right)$, activity duration $\left(B_{i}\right)$ per maintenance visit, arrival periods $\left(\mathrm{K}_{\mathrm{i}}^{\mathrm{r}}\right)$ and number of visits per machine $\left(\mathrm{N}_{\mathrm{i}}\right)$. The model is full of fruitful promise of usefulness in real life situations. However, the shortcomings of the model include its limitation to single-visit situations for facilities. The model could be extended to contain more constraints than the capacity and duration constraints indicated. Another issue is the applicability of the model to a situation where two or more time periods are considered. All these fields are opened up for extension and scrutiny.

Anily et al. [1] studied a discrete problem of scheduling in machines, $M_{,}, \ldots, M_{m}$, in an infinite time horizon discrete time. The cost of operating a machine at any given period, $\mathrm{C}(\mathrm{t}, \mathrm{p})$, is a linear cost structure where each machine $i$ is associated with a constraint $a_{i}$ and the cost of operating the machine in the $\mathrm{j}^{\text {th }}$ period after the last maintenance of that machine is $j \mathrm{a}_{\mathrm{i}}$ for $\mathrm{j} \geq$ 0 . The problem is to find an optimal policy so that the average cost over period $1, \ldots, t$ is a minimum.

Bar-Noy et al. [93] solved the general problem of scheduling in machines $\{1 \ldots \mathrm{m}\}$ for maintenance over an infinite discrete time horizon, in which at most $\mathrm{M}$ machines can be scheduled in each time slot. The schedule with $\mathrm{m}$ machines is $\mathrm{S}=\mathrm{S}_{1}, \mathrm{~S}_{2} \ldots$ where $\mathrm{S}_{\mathrm{t}} \leq$ $\{1, \ldots \mathrm{m}\}$ and $/ \mathrm{S}_{\mathrm{t}} / \leq \mathrm{M}$ for all $\mathrm{t} \geq 1$. Here, $\mathrm{i} \varepsilon \mathrm{S}_{\mathrm{t}}$ means that machine $\mathrm{I}$ is scheduled for maintenance at time-slot $t$. The maintenance cost at time-slot $t$ is $\sum_{\mathrm{i}} \varepsilon_{\mathrm{S}_{\mathrm{t}}} \mathrm{C}_{\mathrm{i}}$. The operating Cost of $(j)$ of machine $j$ at time-slot $t$ is $a_{j}\left(t-t_{1}+b\right)$ for integer $b \geq 0$, where $t_{1} \leq t$ is the largest timeslot at which $\mathrm{j} \varepsilon \mathrm{S}_{\mathrm{t} 1}$. (We assume that all machines are maintained at time slot 0 in $\mathrm{S}$ ). Note that the operating cost is incurred in all time slots, but could be zero at time slot $\mathrm{t}$ if $\mathrm{i} \varepsilon \mathrm{E}_{\mathrm{st}}$ and $\mathrm{b}=0$. We want to find a schedule $\mathrm{S}$ minimizing

$$
\frac{1}{h_{n \rightarrow \alpha}} \sum_{t=1}^{n}\left(\sum_{i \in S T} C i+\sum_{J=I}^{M} O i(j)\right)
$$

\section{IMPORTANT FIELDS OF MS}

Generally, important areas of maintenance where scheduling principles have been applied are the main industries of oil and chemical companies, railways, transport companies, airlines, steel works and discrete part manufacturing. It also includes the public sector such as electricity generation, defence, and infrastructure, for example, roads.

MS research dominates a large portion of contemporary research in operations management. It is a broad stream with two main currents: methods and applications (see figure 1).

The pace and proliferation of research have reached a point where it is beneficial to reflect on what we have learned to date. To this end we asked ourselves what variables represent the concerns of researchers - that is, what variables are being studied, what are similar and different among these variables, how do similar variables relate to each other, and how does 
one distinguish among different variables? In short, is there some way to integrate the findings of the existing studies to enable us to create a common understanding of what has been done to date and where we should go from here or further build on existing knowledge? The scope of work discussed in this section includes approaches, optimality studies, algorithms, techniques, constraints, and limitations. Approaches in MS research include, but are not limited to, multistage [7, 14], system [18, 29, 70], probabilistic [58], fuzzy modelling [10], and CPM network with bill of materials [72]. Also, several effective and efficient techniques have been suggested as alternatives to traditional optimisation-based techniques where the problem size is large and the exact optimal solution is not available. The modern techniques include simulated annealing [5, 47, 71], genetic algorithms [20, 21, 56, 78, 85], heuristics [35, 51, 77], memetics [8], and hybrids [6, 49, 50].

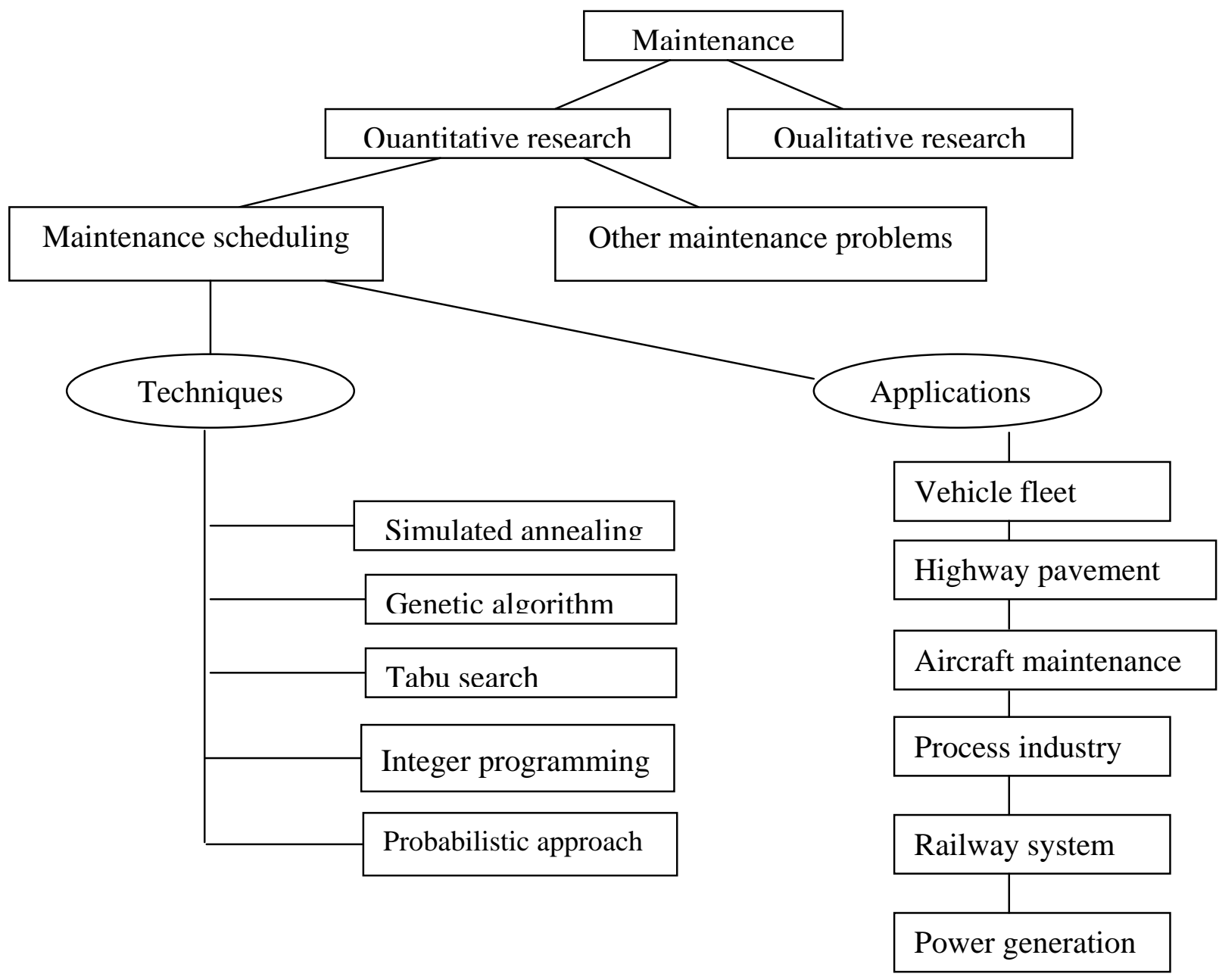

Figure 1: Methods and applications of maintenance scheduling

Various optimisation studies have also been conducted, including by Billinton and colleague [9], Charles-Owaba [13], Christiaanse [15], El-Sharkh [28], Pan [69], Yamayee and associate [86], and Zunn and Quintana [91, 92]. Models have been developed in different situations: proportional intensities [64], full history [43], warranted products [41], finite source [43], uncertainty [54], deregulated system [59], and planning [79]. The constraints under which models operated include: sparse data [63], risk [33], and network [60]. Several tools have also 
been applied [73, 76, 81]. However, simulation appears to be the most significant [45, 57, 75, 83]. Furthermore, among the general MS studies is the work of Anily [1, 2], Dillon [24], Contaxis et al. [17], and others [26, 30, 62, 65, 68, 80, 88]. There are also numerous studies on simultaneous scheduling $[40,44,66]$.

An important distinction between two theoretical papers is the differences in methods or techniques proposed in such work. The literature contains several powerful methods or techniques that have been extensively researched. These methods are representatives of the general theoretical framework or practical perspectives of the methods or techniques in the MS literature. Traditional optimisation techniques such as integer programming, dynamic programming and branch and bound have been proposed to solve diverse problems. These methods give satisfactory solutions for small problems. However, as the size of the problem increases, the size of the solution space increases exponentially and hence also the running time of these algorithms. Other methods that have been employed to overcome this difficulty are modern techniques such as simulated annealing, stochastic evolution, genetic algorithms, tabu search and hybrid algorithm.

Specifically, the literature that deals with the various methods fall into four major categories. The major efforts, perhaps, are those that have been devoted to studying the traditional optimisation-based techniques such as integer programming [1, 2, 5, 6, 22], dynamic programming $[5,6,9,10]$ and branch-and-bound [10, 15, 16, 27] which have been proposed to solve small problems. These methods give an exact optimal solution. A second type of research deals with several modern heuristic methods, including simulated annealing (SA) [71], genetic algorithm (GAs) [5, 20, 21, 78], tabu search [5], and hybrid GAs (HGAs). Another body of literature concentrates on cultural algorithm (CAs), which is a class of models, derived from the cultural evolution process, a hybrid algorithm of a GAs and a guided local search (GLs) procedure. A fourth and growing category of methods deals with heuristic techniques for scheduling maintenance facilities.

\section{CONCLUSIONS AND FUTURE DIRECTIONS}

\subsection{General conclusions}

Quantitative research in MS is professionally respectable and the computer reinforces this respectability. MS is dominated by technically oriented people whose prime knowledge lies in solving technical problems that require analytical tools for maintenance.

In general, studies on MS have reported various applications, including optimal scheduling of overhaul interval of deteriorating and inadequate equipment; MS based on a two-level hierarchical structure of equalized incremental rise; scheduling outage of electricity power plants for maintenance; and scheduling of inspection frequencies for equipment. Studies on simulation have addressed problems of how to simulate preventive failure behaviour of technical systems and methods of predicting maintenance requirements using simulation software. Studies on classical statistics showed the use of statistical tools to solve problems such as the use of delay time analysis.

In this study, the MS literature was reviewed. Based on our observations, we categorised the English-language literature on MS into several distinct structures. 
While the science of MS research is not yet robust, it is educated. Serious work on scheduling is expected to develop an arsenal of optimisation techniques to deal with the non-polynomial hard problems. For that reason, one of the greatest growth areas for the investment of human intelligence is the study of the optimisation techniques and error analysis. There is a need for future empirical research of a comparative nature. For those newly entering this field of study or those young in its pursuit, there is an exciting future filled with important discoveries. Good beginnings have been made, but there is more challenge in recognizing how far one has to go than in drawing satisfaction from past accomplishments.

The paper takes only a first step to encourage investigation and debate on the MS research question. It is suggested, though, that many critical issues have been raised, and some answers have been proffered. The arguments presented here offer a reasonable explanation for the development of the field. The arguments presented here also provide a description that is richer than those previously available on the subject.

Given the needs, capabilities, knowledge, and talents now devoted to the MS problems, the next quarter century offers promises of active and fruitful research and practice in MS.

Thus, we have a population of problems that should keep researchers and practitioners investigating maintenance for decades to come!

\subsection{New directions in MS research}

In recent years, maintenance researchers and practitioners have developed a considerable understanding of the technical matters in MS that were only vaguely understood in the 1960s. Although a good deal has been learnt about MS in a short time, there is much more to know. The present understanding of MS is just sufficient to imply that vast areas are still not understood. The purpose of this section is to propose priority research questions for members of the maintenance community, with an interest in maintenance scheduling.

Significant progress is being made in understanding MS problems. New approaches to more effective analytical tools and strategies offer unique scientific challenges. Thus, there is a need to address the questions and concerns about MS that are raised by the literature, and confirmed by our review. The purpose of this section is to inform the scientific community of broad, shared interests in MS research encompassing various components of the field, and to formulate and foster a wide range of basic and industrial-oriented studies on maintenance scheduling.

From extensive investigations of the literature, a number of research opportunities and directions are apparent. Clearly, the areas of greatest deficiencies are related to modeling, analytical refinements and development of frameworks. Researchers need first to clarify exactly what MS means. The development of a meaningful theory, in turn, will facilitate improved measurement and analysis.

Significant efforts and financial investments are needed in the development of MS software. Researchers and practitioners will benefit immensely if these efforts are based on the relevant dimensions of software from both producers' and consumers' perspectives. The relevant dimensions from a producer's perspective are accuracy, capability, features, completeness, 
conformance, flexibility, serviceability, stability, and structure. From a consumer's perspective, relevant dimensions include capability, communication, completeness, conformance, features, flexibility, simplicity and stability.

An investigation into system behaviour under different types of service of facilities with the use of quantitative analysis tools may be stimulating. Development of new model systems that incorporate single and multiple visits in a holistic model orientation may be a worthwhile investment of efforts. Exploration of discrete models to incorporate inflationary efforts from the perspectives of developed and developing economies may provide useful insight into MS models. Exploration of the role of maintenance/operations scheduling may clarify some seemingly difficult model parameters. Expansion of research on sensitivity analysis of MS models may be helpful to explain the robustness of models and the degree of responsiveness of model parameters.

In focusing specifically on the analytical perspective, care must be taken that it does not constrain theory development. Theory and analysis must begin to look beyond the traditional view if meaningful breakthroughs in understanding MS are to be made. For example, with the application of AHP in MS, AHP is expected to steadily expand to cover a whole range of sectors such as oil, manufacturing, etc. The range is expected to grow considerably. The extension of AHP into MS may be a major development both academically and practically. It could open up for speculation and research a wide range of problems. An example of such a problem is the relationship between prioritised criteria such as cost, time and other elements.

The disadvantages, drawbacks, accuracy and computer time of various MS problems have also been pointed out. The area of great potential for the application of analytical hierarchy process (AHP) methodology in studying MS lies in a study of prioritised criteria, particularly, using criticality and cost of investment of facilities to be scheduled. A survey of major research papers on MS literature establishes clearly that there are limited references to the concept of AHP in maintenance.

In general, many current researchers on MS do not study deep structures of MS problems. The inability of researchers to probe these deep structures cannot be attributed to their unwillingness to engage in intensive research tools. The author believes that the application of the AHP methodology in analysing and solving MS problems provides an answer. The intention is that this paper will serve as a catalyst in stimulating MS researchers to consider AHP methodology in order to reveal deeper structures of MS problems.

\section{REFERENCES}

[1] Anily, S., Glass, C.A. and Hassin, R., 1998, The scheduling of maintenance service, Discrete Applied Mathematics, 82, pp. 27-42.

[2] Anily, S., Glass, C.A. and Hassin, R., 1999, Scheduling of maintenance services to three machines, Annals of Operations Research, 86, pp. 375-391.

[3] Alfares, H.K., 1999, Aircraft maintenance workforce scheduling, A case study, Journal of Quality in Maintenance Engineering, 5(2), pp. 78-88.

[4] Ashayeri, J; Teelen, A and Selen W., 1996, A production and maintenance planning model for the process industry. International Journal of Production Research, 34 (12), pp. 3311-3326. 
[5] Burke, E.K., Clark, J.A., Smith, A.J., Four methods for maintenance scheduling, In Proceedings of the International Conference on Artificial Neural Networks and Genetic Algorithms, pp. 264-269, Springer.

[6] Burke, E.K., Smith, A.J., 1997, Hybrid Evolutionary Techniques for the Maintenance Scheduling Problem, The IEEE Power Engineering Society Transactions.

[7] Burke, E.K. and Smith, A.J., 1999, A Multi-stage approach for the thermal generator maintenance scheduling problem, Proceedings of the Congress on Evolutionary Computation (CE’99), Washington DC, USA (IEEE Press), 2, pp. 1085-1092.

[8] Burke, E.K. and Smith, A.J., 1999, A Memetic algorithm to schedule grid maintenance, Proceedings of the International Conference on Computational Intelligence for Modelling Control and Automation: Evolutionary Computation and Fuzzy Logic for Intelligent Control, Knowledge Acquisition and Information Retrieval, Vienna, IOS Press, pp. 122-127.

[9] Billinton, R. and Pan, J., 1998, Optimal maintenance scheduling in a two identical component parallel redundant system, Journal of Reliability Engineering and System Safety, 59(3), pp. 309-316.

[10] Coudert, T. Grabot, B. Archimede, B., 2000, Integration of maintenance constraints in scheduling: fuzzy modelling and multi-agent approach, $4^{\text {th }}$ IEEE/IFIP International Conference on Information Technology for Balanced Automation Systems in Production and Transportation (BASYS 2000), Berlin, Allemagne, 27-29, in Advances in Networked Entreprises, L.M. Camarinha-Matos, H. Afsarmanesh, H.H. Erbe Eds, Kluwer, 2000, pp. 297-304.

[11] Creemers, T. Ros, L., Riera, J., 1994, Constraint-based maintenance scheduling on power-distribution networks. Cybernetics Institute. IC-DT 9409.

[12] Cheu, R.L., Wang, Y. and Fwa, T.F., 2001, Scheduling of pavement maintenance to minimise traffic delay, Proceedings of the PES-CTR Symposium of Pavement Technology, Singapore.

[13] Charles-Owaba, O.E., 2000, An optimal model for gantt charting multiple machines' preventive activities, NIIE Conference Proceedings (Book of Abstracts)

[14] Chen, L.N., Toyoda, J., 1990, Maintenance scheduling based on two level hierarchical structure to equalize incremental risk, IEEE Transactions on Power Systems, 5(4), pp. 1510-1516.

[15] Christiaanse, W.R., 1973, A program for calculating optimal maintenance schedules recognising constraints, 1973 PICA Conference Proceedings, pp. 230-239.

[16] Christiannse, W.R., Palmer, A.H., 1991, 'A technique for automatic scheduling of the maintenance of generating facilities, IEEE Transactions on Power Apparatus and Systems, PAS-91 (1), pp. 319-327.

[17] Contaxis, G.C., Kavatza, S.D. Vournas, C.D., 1989, An interactive package for risk evaluation and maintenance scheduling, IEEE Transactions on Power Systems, 4(2), pp. 389, 395.

[18] Chattopadhyay, D., Bhattacharya, K., Pariksh, J., 1995, A system approach to leastcost maintenance scheduling for an interconnected power system, IEEE Transactions on Power Systems, 10(4), pp. 2000-2007.

[19] Charest, M. and Ferland, J.A., 1993, Preventative maintenance scheduling of power generation units, Annals of Operational Research, 41, pp. 185-206.

[20] Dahal, K. P. and McDonald, J.R., 1997, Generational and steady state genetic algorithms for generator maintenance scheduling problems, Proceedings of the International Conference on Artificial Neural Networks and Genetic Algorithms, pp. 
260-264.

[21] Dahal, K.P. and McDonald, J.R., 1997, Generator maintenance scheduling of electric power systems using genetic algorithms with integer representation, Submitted to GALESIA '97.

[22] Dapazo, J.F. and Merrill, H.M., 1975, Optimal generator maintenance scheduling using integer programming.IEEE Transactions on Power Apparatus and Systems, PAS94(5): 1537-1545.

[23] De Campos, F. C. and Belhot, R.V., 1994, Maintenance management of vehicle fleets: a review. Gestao \& Producao (Brazil), 1(2), p. 171-189.

[24] Dillon, T.S., 1983, Maintenance scheduling. Invited paper. In M.G. Sign, ed. Encyclopaedia of systems and control. UK, Pergamon Press.

[25] Duffuaa, S.O., Al-Sltan, K.S., 1997, Mathematical programming approaches for the management of maintenance planning and scheduling, Journal of Quality in Maintenance Engineering, 3, pp. 163-76.

[26] Duffuaa, S.O. and Ben-Daya, M., 1994, An extended model for the joint overhaul scheduling problems, International Journal of Operations Management, 14(7), pp. 3743.

[27] Egan, G.T., Dillon, T.S., Morsztyn, K., 1976, An experimental method of determination of optimal maintenance schedules in power system using branch and bound techniques IEEE Transactions on Man. and Cybernetics. SMC-6(8), pp. 538537.

[28] El-Sharkh, M.Y., Yasser, R., El-Keib, A.A., 1998, Optimal maintenance scheduling for power generation systems - a literature review, Maintenance and Reliability Conference Proceedings MARCON 98, 1, pp. 20.01-20.10.

[29] El-Sheikhi, F.A., Billinton, R., 1984, Generating unit maintenance scheduling for single and two interconnected systems, IEEE Transactions on Power Apparatus and Systems, PAS-103(5), pp. 1038-1044.

[30] Enscore, E.E. and Burns, D.L., 1983, Dynamic scheduling of a preventive maintenance programme, International Journal of Production Research, 21(3), pp. 357368.

[31] Federgruen A. and So K.C., 1990, Optimal maintenance policies for single server queuing system subject to breakdown, Operations Research, 38(2).

[32] Fwa, T.F., Cheu, R.L. and Muntasir, A., 1999, Scheduling of pavement maintenance to minimise traffic delays, Transportation Research Record 1650, Transportation Research Board, Washington, D.C., 28-35.

[33] Garver, L.L., 1972, Adjusting maintenance schedule to levelize risk, IEEE Transactions on Power Apparatus and Systems, PAS-91(5), pp. 2057-2063.

[34] Goheen L.C., 1977, On the Optimal operating policy for the machine repair problem when failure and repair times have erlang distribution, Operations Research, 25(3).

[35] Gunn, E.A. and Lee, B.P., 1991, Lagrangian relaxation and integer programming heuristics for vehicle fleet maintenance scheduling, Paper Presented at International Symposium on Mathematical Programming, Amsterdam.

[36] Haghani, A. and Shafahi, Y., 2002, Bus maintenance systems and maintenance scheduling: Model formulation and solutions, Transportation Research Part A: Policy and Practice (issue): 36(5), pp. 453-458.

[37] Hall, R.W., 2000, Scheduling transit railcar maintenance and facility design, Transportation Research, V. 34A, pp. 67-84.

[38] Hariga, M., 1994, A Deterministic maintenance scheduling problem for non-identical 
machines, International Journal of Operations Management, 4(7), pp. 27-36.

[39] Higgins, A., Ferreira, L. and Lake, M., 1999, Scheduling rail track maintenance to minimise overall delays, Chapter 10, pp. 779-796. In: Transportation and traffic theory, Ceder, A. (ed), Pergamon, Kidington, Oxford.

[40] Joshi, S.; Gupta, R., 1996, Scheduling of routine maintenance using production schedules and equipment failure history, Computer and Industrial Engineering, 10(1), $11-20$.

[41] Jack, N., Murthy, D.N.P., 2001, Optimal preventive maintenance scheduling for maintenance of warranteed products, $4^{\text {th }}$ IMA Conference on Modelling in Industrial Maintenance and Reliability Decision Support in the New Millennium, UK.

[42] Khatib, H., 1979, Maintenance scheduling of generating facilities, IEEE Transactions on Power Apparatus and Systems, PAS-98(5), pp. 1604-1608.

[43] Kobbacy, K. A. H., Fawzi, B. B., Percy, D. F., Ascher, H. E., 1997, A full history proportional hazards model for preventive maintenance scheduling, Quality and Reliability Engineering, 13, pp. 187-198.

[44] Kramer, F., and Bai, S.X., 1996, Optimal control of a production system with periodic maintenance, OCAM (U.K.) 17(4), pp. 281 - 307.

[45] Kripa S., 1983, A simulation model for maintenance scheduling of a group of machines. Proceedings of Conference on Modern Prod. \& Management Techniques for Business and Industry, Chulalongkorn University, Bangkok, pp. CS-20 - 38.

[46] Koole, G.M. and Vrijenhoek, M., 1995, Scheduling a repairman in a finite source system. Report TW 95-03, Leiden University.

[47] Kiziliarmakli, A.V., 1982, Simulation study of dynamic job shop rules in maintenance scheduling, Unpublished M. Eng. Thesis, Department of Industrial Engineering, Dalhousie University.

[48] Kurban, M., 1999, The maintenance schedule optimisation in an interconnected power system using the levelised risk method, IEEE Budapest Power Tech '99 Conference, Budapest, Hungary, 386-26, 40.

[49] Kin, H. and Nara, K.A., 1995, A method for maintenance scheduling using GA combined with SA, Trans. IEEE Japan, 115-B(11).

[50] Kin, H. Hayashi, Y., Nara, K., 1997, An algorithm for thermal unit maintenance scheduling through combined use of GA, SA and TS, IEEE Transactions on Power Systems, 12, pp. 329-335.

[51] Lake, M., Ferreira, L. and Kozan, E., 2001, Heuristic techniques for scheduling railway track maintenance. In: Operations research/management science at work, Kozan and Ohuchi (Eds.) The International Series in Operations Research \& Management Science, Kluwer Academic Publisher.

[52] Lake, M. and Ferreira, L., 2001, Considering the risk of delays in scheduling railway track maintenance, Proceedings of the $7^{\text {th }}$ International Heavy Haul Conference, International Heavy Haul Association Inc., Virginia Beach, VA, USA, pp. 367-372.

[53] Lake, M., Ferreira, L. and Murray, M., 2000, Minimising costs in scheduling railway track maintenance, Chapter 13, pp. 895-902. In: Computer in railways VII, Allan, Hill, Brebbia, Scuitto and Sone (eds), WIT Press, Southampton.

[54] Lund, J.R., 1990, Scheduling maintenance dredging on a single reach with uncertainty, Journal of Waterway, Port, coastal, and ocean engineering, ASCE, 116(2), pp. 211-321.

[55] Lee, P., 1991, Integer programming approaches to vehicle fleet maintenance scheduling, Unpublished M.A.Sc Degree Thesis, Department of Industrial Engineering, Dalhousie University. 
[56] Langdon, W.B., 1996, Scheduling maintenance of electric power transmission networks using genetic programming, Research Note RN/96/49, University.

[57] Mest, B.A., 1980, Simulation model of a maintenance planning and scheduling system using dynamic rules and order importance, Unpublished M. Eng. Thesis, Department of Industrial Engineering, Dalhousie University.

[58] Marwali, M.K.C., Shahidehpour, S.M., 1999, A probabilistic approach to generation maintenance scheduler with network constraints, International Journal of Electrical Power and Energy Systems 21(8), pp. 533-545.

[59] Marwali M. and Shahidehpour, M., 1998a, Coordination of short-term and long-term transmission maintenance scheduling in a deregulated system, IEEE Power Engineering Letters, 1(1), pp. 46-48.

[60] Marwali, M. and Shahidehpour, M., 1998b, Integrated generation and transmission maintenance scheduling with network constraints, IEEE Transactions on Power Systems, 13(3), pp. 1063-1068.

[61] Mosley S.A., Teyner T., Uzsoy R.M., 1998, Maintenance scheduling and staffing policies in a wafer fabrication facility, IEEE Transactions on Semiconductor Manufacturing, 11(2), pp. 316 - 323.

[62] Percy, D.F., Ascher, H.E. Kobbacy, K.A.H., 1997, Issues concerning effective modelling/analysis of preventive maintenance scheduling, University of Salford Departmental Note MCS-97-08.

[63] Percy, D.F., Kobbacy, K.A.H and Fawzi, B.B., 1997, Setting preventive maintenance schedules when data are Sparse, Int J of Prod. Econ. 51, pp. 223-234.

[64] Percy, D, Kobbacy, K, Ascher, H.T., 1998, Using proportional-intensities models to schedule preventive maintenance intervals, IMA Journal of Mathematical Applied in Business and Industry, 9, 289-302.

[65] Paz, N.M. and Leigh, W., 1994, Maintenance scheduling: Issues, results and research needs, International Journal of Operations \& Production Management, 14(8), pp. 4769.

[66] Ram, B. and Olumolade, M., 1987, Preventive maintenance scheduling in the presence of a production plan, Production and Inventory Management, 8, pp. 81-89.

[67] Nguyen D.G. and Murthy D.N.P., 1981, Optimal repair limit replacement policies with imperfect repair, J. Opl. Res. Soc. 32, pp. 409-416.

[68] Olorunniwo F.O; Izuchukwu A., 1991, Scheduling imperfect preventive and overhaul maintenance, International Journal of Quality \& Reliability Management, 8(4).

[69] Pan J., 1996, Optimal maintenance scheduling for power system reliability applications, Unpublished Master Thesis, Department of Electrical Engineering, University of Saskatchewan.

[70] Rao, N.K., Scheduling optimal maintenance times for a system based on component reliabilities, Ph.D. Dissertation, Department of Industrial and Systems Engineering.

[71] Satoh, T. and Nara, K., 1991, Maintenance scheduling by using the simulated annealing method, IEEE Transactions on Power Systems, 6, pp. 850-857.

[72] Samaranayake, P., 1999, Scheduling for maintenance using merged CPM networks with MRP bills-of-materials, Second World Manufacturing Congress (WMC'99), University of Durham, U.K.

[73] Samaranayake, P., 2001, An integrated approach to assembly/maintenance logistics scheduling using modified BOM and operations routing, International Conference on Logistics and Supply Chain Management, Coimbatore, India.

[74] Samaranayake, P., Lewis, G., Woxvold, E.R.A., and Tocich, D., 2002, Development 
of engineering structures for scheduling and control of aircraft maintenance, International Journal of Operations and Production Management, 22(7).

[75] Shafahi, Y., Haghani, A., 1998, A simulation analysis of optimisation-based bus transit maintenance scheduling, Department of Environmental Engineering, University of Maryland.

[76] Simic Z., Follen S., Mikulicic, V., 1997, On-line monitor approach (P), ESR-EL '97 Conference.

[77] Silver, E.A. and Murphy, G.F., 1994, Cost analysis and extension of a simple maintenance scheduling heuristic, NRL (U.S.) 41(7), pp. 945 - 958.

[78] Sriskandarajah, C., Jardine, A.K.S., and Chan, C.K., 1998, Maintenance scheduling of rolling stocks using a genetic algorithm, Journal of Operational Research Society (U.K.), 49, pp. 1130-1145.

[79] Stremel, J.P., 1981, Maintenance scheduling for generation system planning, IEEE Transactions on Power Apparatus and Systems, PAS-100(3), pp. 4010-4019.

[80] Stremel, J.P., Jenkins, R.T., 1981, Maintenance scheduling under uncertainty, IEEE Transactions on Power Apparatus and Systems, PAS-100(2), pp. 460-465.

[81] Taylor, R. W., 1996, A linear programming model to manage the maintenance backlog, Omega (U.K.) 24(2), pp. 217 - 227.

[82] Wang, Y., Cheu, R.L. and Fwa, T.F., 2002, Highway maintenance scheduling using genetic algorithm with microscopic traffic simulation, Proceedings of the $81^{\text {st }}$ Annual Meeting of the Transportation Research Board, in CD-ROM.

[83] Wang Y. A., 2002, Hybrid genetic algorithm-simulation methodology for pavement maintenance scheduling, Unpublished M. Eng. Dissertation, Department of Industrial Engineering, National University of Singapore, Singapore.

[84] Walker, L., Bryan, U. and Turner, K., 2001, Scheduling preventive maintenance of transmission circuits, $4^{\text {th }}$ IMA Conference on Modelling in Industrial Maintenance and Reliability Decision Support in the New Millennium, April, 2001, UK.

[85] Wang, Y., Cheu, R.L. and Fwa, T.F., 2001, Highway maintenance scheduling using genetic algorithm with microscopic traffic simulation, Proceedings of the $81^{\text {st }}$ Annual Meeting of the Transportation Research Board, in CD-ROM.

[86] Yamayee,Z.A., Sidenblad, K and Yoshimura, M., 1998, A computationally efficient optimal maintenance scheduling method. IEEE Transactions on Power Apparatus and Systems, 102(2), pp. 330-338.

[87] Yang Tai-Fu T., 1997, Investigation of single machine scheduling with scheduled preventive maintenance, Unpublished Thesis, Department of Industrial Engineering, Texas Tech University.

[88] Yamayee, Z.A., 1982, Maintenance scheduling: description, literature survey, and interface with overall operation scheduling, IEEE Transactions on Power Systems, PAS-101(8), pp. 2770-2779.

[89] Yellen, J., Al-Khamis, J., Vemuri, S. and Lemonidis, L., 1992, Unit maintenance scheduling with fuel constraints; IEEE Transactions on Power Systems, 7, pp. 726-733.

[90] Yellen, J. and Al-Khamis, T., 1995, Refinery unit maintenance scheduling using integer Programming, Applied Mathematical Modelling, 19.

[91] Zurn, H.H., Quintana, V.H., 1977, Several objective criteria for optimal generator preventive maintenance scheduling, IEEE Transactions on Power Apparatus and Systems, PAS-96(3), pp. 984-922.

[92] Zurn, H.H. and Quintana, V.H., 1975, Generator maintenance scheduling via successive approximations dynamic programming. IEEE Transactions on Power 
Apparatus and Systems, 94(2), pp. 665-671.

[93] Bar-Noy A., Bhatia R., Naor J., Schieber B., 1998, Minimizing service and operation costs of periodic scheduling, Conference Proceeding of SODA'98.

\section{Aknowledgement}

The author thanks Professor J.K. Visser, University of Pretoria, South Africa for his comments on an earlier draft of this article. In addition, thanks to Dr. O. E. Charles-Owaba, under whom the research was conducted while the author was a Ph.D. student at the University of Ibadan, Nigeria. 